\title{
O dia em que virei índio - a identificação ontológica com o outro como metamorfose descolonizadora
}

\author{
[ The day I became indigenous - the ontological identification \\ with the other as decolonizing metamorphosis
}

\section{Renzo Taddei ${ }^{\mathrm{I}}$}

RESUMO - Este texto combina reflexões sobre as dificuldades encontradas em meu trabalho etnográfico junto à Fundação Cacique Cobra Coral, em especial no que diz respeito a transformações na forma como a alteridade foi vivida ao longo do processo etnográfico, com críticas de antropólogos indígenas à antropologia e suas práticas, de modo a fazer com que elementos da pesquisa etnográfica iluminem, na medida do possível, dimensões pouco compreendidas das referidas críticas. O texto então busca oferecer algumas reflexões sobre os impactos do aparecimento de todo um contingente de antropólogos declaradamente "animistas" dentro de um contexto em que a antropologia tacitamente reproduz, em algumas de suas práticas, o naturalismo materialista das ciências ditas "duras". • PALAVRAS-CHAVE • Animismo; espiritualismo; umbanda; antropologia indígena; descolonização da antropologia. •
ABSTRACT - This text combines reflections on the challenges encountered by me in my ethnographic work with the Cacique Cobra Coral Foundation, in special in what concerns the transformation in the way alterity was experienced throughout the ethnographic process, with criticisms made by indigenous anthropologists to anthropology and its practices, with the goal of making elements of the ethnographic research illuminate, as much as possible, uncomprehended dimensions of the mentioned criticisms. The text then offers some reflections on the impacts of the appearance of the whole contingent of self-declared "animist" anthropologists, in a context in which anthropology tacitly reproduces, in some of its practices, the materialistic naturalism of the so called "hard" sciences. - KEYWORDS • Animism; spiritualism; umbanda; indigenous anthropology; decolonization of anthropology.

Recebido em I8 de janeiro de 2018

Aprovado em 7 de março de 2018

TADDEI, Renzo. O dia em que virei índio - a identificação ontológica com o outro como metamorfose descolonizadora. Revista do Instituto de Estudos Brasileiros, Brasil, n. 69, p. 289-306, abr. 2018.

DOI: http://dx.doi.org/Io.II606/issn.2316-90IX.voi69p289-306

I Universidade Federal de São Paulo (Unifesp, Santos, SP, Brasil). 


\section{PARTe I}

$\mathrm{O}$ argumento central deste texto se constrói em torno de três elementos. O primeiro diz respeito ao fato de que a existência da antropologia, enquanto disciplina acadêmica multinacional, funda-se na adoção tácita dos pressupostos ontológicos em voga desde o contexto sociocultural de sua fundação, a saber, o naturalismo materialista novecentista imperante no meio acadêmico em países como Inglaterra, França, Alemanha e Estados Unidos. A despeito do notável desenvolvimento teórico da disciplina ao longo do século XX, tais pressupostos ontológicos mantiveram-se intocados. Nas últimas décadas do século, no entanto, o desenvolvimento da antropologia em países que foram colônias europeias e a expansão das oportunidades educacionais a populações autóctones produziram, nos Estados Unidos, no Canadá, na Índia, na Austrália, na Nova Zelândia, no México, no Brasil e em diversos outros países, acadêmicos treinados em antropologia, mas que não coabitam o naturalismo materialista acima mencionado. Particularmente no Brasil, cresce o número de antropólogos indígenas; cresce, também, o volume de acusações a respeito das práticas colonialistas que, dizem eles, caracterizam a disciplina.

O segundo elemento está relacionado ao sucesso da teoria do perspectivismo ameríndio, o que deu visibilidade inédita aos temas indígenas, fora dos domínios da etnologia; sua associação com as filosofias de Bruno Latour, de Isabelle Stengers e de Patrice Maniglier, além de alianças com a antropologia melanésia de Marilyn Strathern e Roy Wagner, reposicionou o pensamento indígena em chave de centralidade no contexto das discussões dos problemas contemporâneos, dentro e fora da academia. Como diz Viveiros de Castro no prefácio à edição brasileira do livro A queda do céu $u^{2}$, de Davi Kopenawa e Bruce Albert, "temos a obrigação de levar absolutamente a sério o que dizem os índios"3. O que inclui, naturalmente, o que dizem os antropólogos indígenas sobre as práticas instituídas na disciplina.

2 KOPENAWA, Davi; ALBERT, Bruce. A queda do céu: palavras de um xamã yanomami. São Paulo: Companhia das Letras, 2015 .

3 VIVEIROS DE CASTRO, Eduardo. O recado da mata. In: KOPENAWA, Davi; ALBERT, Bruce. A queda do céu: palavras de um xamã yanomami. São Paulo: Companhia das Letras, 20I5, p. I5 (ênfase no original). 
E, finalmente, o terceiro refere-se a como o estranhamento, por parte dos antropólogos indígenas, da atitude acadêmica que esvazia as práticas dos povos com que trabalham, sob rótulos como "cultura" e assemelhados, abre as portas para a articulação discursiva de outros outros, que se sentem igualmente alienados. Uma das questões centrais - ainda que não a única - no conflito entre antropólogos indígenas e o mainstream acadêmico diz respeito às entidades que existem fora do radar das ciências "duras”; ciências estas que se arrogam autoridade exclusiva na definição do que (não) existe. Um exemplo notório são os espíritos xapiri, personagens fundamentais na existência do povo Yanomami. Ocorre, no entanto, que o "animismo"4 yanomami e dos demais povos indígenas sul-americanos é, em certo sentido ontológico, compatível - talvez seja mais preciso dizer aliançável - com outros animismos, como os que encontramos nos candomblés, nas umbandas, nas juremas, nos tambores de mina, nas religiões ayahuasqueiras, nas distintas tradições de pajelança, nos kardecismos, nos xintoísmos, nos budismos, nos hinduísmos, e em várias outras tradições espiritualistas presentes no país.

O objetivo deste texto é explorar as implicações das críticas de antropólogos indígenas à antropologia e da possibilidade de que tais críticas, justamente pelo potencial que têm de capitanearem alianças com outras tradições espiritualistas, possam - se tomadas a sério - desestabilizar a disciplina. A apresentação das atividades de minha pesquisa etnográfica com a Fundação Cacique Cobra Coral e os desafios e impasses nela encontrados serão usados como material sobre o qual o argumento será construído. O gênero que vou usar é o autobioetnográfico; o texto tem orientação mais sintética do que analítica.

\section{Parte 2}

O trabalho etnográfico do meu doutorado centrou-se nos conflitos entre populações sertanejas, cientistas, políticos e jornalistas no que diz respeito a formas de entender e viver o clima no Ceará. A etnografia desenvolveu-se na agência meteorológica estadual e também junto a algumas lideranças comunitárias sertanejas chamadas de "profetas da chuva", em função de sua capacidade de transformar observações do ecossistema em previsões de chuva.

4 Animismo é um termo de origem colonial e que caracteriza a visão que o materialismo naturalista europeu tem dos demais povos do mundo. O trabalho de Philippe Descola (2013) é exemplar nesse sentido. Da mesma forma como Daniel Munduruku (20I7) afirmou que "não existem índios no Brasil”, não existem animistas a não ser na mente de quem está imerso em um contexto materialista. No entanto, o conceito de animismo será usado neste texto - a partir deste ponto sem as aspas - por duas razões: a desconstrução do conceito não é o objetivo central deste trabalho, e, mais importante, o argumento aqui apresentado tem como interlocutor o fundamento naturalista comumente encontrado na antropologia. A adoção do conceito é, assim, uma concessão no sentido de facilitar o diálogo. DESCOLA, Philippe. Beyond nature and culture. Chicago: University of Chicago Press, 20I3; MUNDURUKU, Daniel. Índio não existe. Global Editora, julho 20I7. Disponível em: <http://www.globaleditora.com.br/blog/estante-global/daniel-munduruku-indio-nao-existe2 >. Acesso em: 27 dez. 2017 . 
Em maio de 2007, fui à Universidade de Miami para o lançamento do documentário One water, do diretor de cinema Sanjeev Chatterjee, para o qual eu havia colaborado. Ali ocorreu algo que tomo como momento inaugural desta pesquisa. No coquetel que antecedeu a projeção do filme, fui colocado em uma roda de conversa onde um homem estava trajado como lama tibetano. Tratava-se de um assessor pessoal do Dalai Lama; este participara do documentário, mas não havia podido comparecer ao seu lançamento, e por isso enviou o assessor como seu representante. Em determinado momento da conversa, uma funcionária da universidade disse que, sempre que um furacão se aproximava de Miami, escrevia ao lama e pedia a ele que orasse, de modo a alterar sua trajetória. Todos riram - com exceção da mulher e do lama, o que criou um clima de constrangimento entre todos, e as risadas logo se extinguiram. O lama disse então, com ar benevolente, que não acreditava possuir esse poder. No entanto, quando era um aprendiz, disse ele, viu seu mestre subir em uma montanha e parar uma tempestade.

Eu vinha estudando a atividade de prever as condições de atmosfera, seja de forma científica, seja através dos ditos conhecimentos tradicionais, há vários anos; mas não havia me deparado com a questão da alteração intencional de tais condições. Ali algo novo e interessante se apresentava.

Anos mais tarde, foi através da imprensa, no Rio de Janeiro, que conheci a Fundação Cacique Cobra Coral. Trata-se de uma instituição religiosa, ligada à tradição da umbanda, que trabalha para parceiros públicos e privados alterando as condições atmosféricas. $\mathrm{O}$ espírito do Cacique Cobra Coral é quem opera as alterações atmosféricas; sua comunicação com os vivos se dá através da médium Adelaide Scritori; e a comunicação de ambos, espírito e médium, com o mundo se faz através do relações-públicas da fundação, Osmar Santos. A sede da fundação está localizada na cidade de Guarulhos, estado de São Paulo, ainda que, historicamente, a maioria dos trabalhos realizados tenha ocorrido na cidade do Rio de Janeiro. Mais uma vez eu encontrava referência à alteração intencional das condições atmosféricas. Dessa vez, decidi adotar a questão como tema de pesquisa.

\section{PARTe 3}

Esta pesquisa ainda está em curso; o ponto de interesse, aqui, é o fato de que ela, desde o primeiro momento, me colocou desafios existenciais e metodológicos para os quais eu não havia sido treinado. O relato abaixo descreve tais desafios.

Em um texto anterior ${ }^{5}$ apresentei o trabalho da Fundação Cobra Coral em mais detalhe; recapitulo alguns elementos mais relevantes para o argumento aqui desenvolvido. Nos últimos 30 anos a fundação teve contratos de prestação de serviço, publicados em diário oficial, assinados com as prefeituras do Rio de Janeiro e São Paulo, os governos estaduais do Rio de Janeiro, Santa Catarina e Rio Grande do Sul, e o governo do Distrito Federal, e com empresas como a Artplan, organizadora

5 TADDEI, Renzo. Alter geoengenharia. In: Meteorologistas e profetas da chuva: conhecimentos, práticas e políticas da atmosfera. São Paulo: Terceiro Nome, 20I7, p. I89-205. 
do Rock in Rio . Os contratos envolvem a produção de chuvas ou de tempo seco. Previsivelmente, as atividades da fundação são cercadas por controvérsias e ataques de todos os tipos.

Um dos colegas meteorologistas com quem trabalhei em minha pesquisa anterior postou na internet, em determinada ocasião, a acusação de que a fundação era uma fraude, porque "todos sabem que há meteorologistas trabalhando para eles". Através da internet e de outros colegas meteorologistas, descobri que, efetivamente, a fundação contrata meteorologistas de alto nível para atuarem como consultores em suas operações. Mais adiante, Osmar Santos não só confirmou a relação com os cientistas, como me passou os seus contatos.

No momento atual há dois cientistas que prestam serviço de forma mais sistemática à fundação: um é um professor aposentado do Instituto de Astronomia, Geofísica e Ciências Atmosféricas da Universidade de São Paulo (IAG/USP); o outro, mais jovem, é pesquisador do Centro de Previsão do Tempo e Estudos Climáticos do Instituto Nacional de Pesquisas Espaciais (CPTEC/Inpe). Trata-se, nada menos, das duas instituições meteorológicas mais prestigiosas do país. Desnecessário dizer que o corpo diretivo de ambas as instituições não aprova tais atividades, e por essa razão os meteorologistas pedem que seus nomes não sejam mencionados.

Eu entrevistei os dois meteorologistas em múltiplas ocasiões. O que me parece mais intrigante na pesquisa, além da relação de uma instituição da natureza da fundação com pessoas públicas e jurídicas de tamanha visibilidade, é a relação com tais cientistas - e aqui a pesquisa se conecta com meus trabalhos anteriores. Por isso decidi investir nesta dimensão do trabalho da entidade.

Frente ao questionamento de por que a fundação precisa de meteorologistas, o relato de Osmar Santos foi idêntico ao que obtive dos cientistas. O Cacique Cobra Coral é uma entidade espiritual capaz de operar transformações nas condições atmosféricas. Através da médium Adelaide Scritori, ele coloca esse poder à disposição de quem dele necessite. O resultado nunca é garantido, diz Osmar, porque o bem comum está acima dos interesses pessoais ${ }^{7}$, e o atendimento de pedidos depende da questão do merecimento. No entanto, parceiros como o ex-prefeito do Rio de Janeiro, Cesar Maia, por exemplo, afirmam que a eficácia do Cacique é garantida ${ }^{8}$.

Ocorre que o Cacique solicita aos meteorologistas relatórios sobre as condições atmosféricas sobre a região e no momento onde o trabalho deve ser realizado, e também explicações sobre o funcionamento dos sistemas atmosféricos, incluindo

6 NEVES, Marcos Eduardo. Vendedor de sonhos: a vida e a obra de Roberto Medina. São Paulo: Melhoramentos, 2006, p. I85-I86.

7 Segundo Osmar Santos, o cacique só aceita fazer um trabalho quando é convencido que os impactos do mesmo são do interesse comum. Na abertura dos jogos olímpicos de 20I2, em Londres, por exemplo, foi a ocorrência de uma seca na Espanha, para onde a umidade que vinha do Atlântico Norte foi enviada, que garantiu a operação. Ver: TAS, Marcelo. Cacique Cobra Coral: medalha de ouro na abertura da Olimpíada. Blog do Tas, 28/12/20I2. Disponível em: <http://blogdotas.com.br/20I2/07/28/cacique-cobra-coral-medalhade-ouro-na-abertura-da-olimpiada $>$. Acesso em 27 dez. 2017.

8 BOULTING, Gideon et al. Série O infiltrado, episódio n. 9- Magia. History Channel. Disponível em: <https:// www.youtube.com/watch?v=ESh54fsi8iU >. Acesso em: 27 dez. 2017. 
instruções sobre como proceder para atingir determinado objetivo. No primeiro contato de Osmar Santos com o professor da USP, nos anos I980, o primeiro perguntou por telefone ao segundo, que à época atuava também como meteorologista do jornal O Estado de S. Paulo, o que deveria ser feito para evitar que uma frente fria que vinha da Argentina adentrasse o território brasileiro. Após ser convencido de que não se tratava de uma brincadeira, o meteorologista sugeriu que, se a pressão atmosférica sobre a região aumentasse, isso teria o efeito de desfazer a nebulosidade, dissolvendo a frente fria. Segundo o professor, o fato de que a pressão atmosférica efetivamente subiu na região, nos dias posteriores, fez com que ele decidisse seguir em contato com a fundação, movido por curiosidade. Posteriormente, o cientista viria a se transformar em diretor técnico da instituição.

Reproduzo abaixo outro exemplo, mais recente, citado em um texto anterior:

Eu já vi isso acontecer... eles seguram a frente fria na porta de entrada do Rio de Janeiro. [...]. É como no Rock in Rio, foi uma coisa incrível - uma baita frente fria encostando lá, e eles seguraram ela. Eles me perguntaram: como eu faço pra não deixar essa frente fria entrar? Em primeiro lugar eu digo: é preciso reforçar o vento nordeste, contra o deslocamento da frente, pra segurá-la; tem que mudar também o cavado de altitude de oeste, retardando a sua propagação... a meteorologia trabalha em distintas altitudes...?.

Na mesma entrevista, eu pergunto como exatamente o cacique altera as condições atmosféricas. "A Adelaide me disse que o mundo espiritual é muito organizado", disse ele, "há equipes imensas que cuidam da umidade do ar, outras que cuidam da temperatura, outras que cuidam da pressão, e assim sucessivamente”. Foi nesse momento, então, que algo inesperado ocorreu: ele começou a vasculhar a pasta de recortes sobre a fundação que havia trazido para me mostrar, à procura de alguma coisa. Depois de algum tempo encontrou o que buscava; passou-me algumas folhas de papel, com o timbre da fundação, nas quais haviam sido fotocopiadas páginas de $O$ livro dos espíritos, de Alan Kardec. Trata-se de um dos livros considerados fundacionais do espiritismo kardecista, publicado em I857, na França, com questões colocadas por Kardec a espíritos, através de médiuns. O texto fotocopiado reproduzia a seção "Ação dos espíritos nos fenômenos da natureza". Reproduzo abaixo trechos mais significativos:

536. [...]b) - [...] sabendo que os Espíritos exercem ação sobre a matéria e que são os agentes da vontade de Deus, perguntamos se alguns dentre eles não exercerão certa influência sobre os elementos [na Natureza] para os agitar, acalmar ou dirigir?

"Mas, evidentemente. Nem poderia ser de outro modo. Deus não exerce ação direta sobre a matéria. Ele encontra agentes dedicados em todos os graus da escala dos mundos.”

[...]

539. A produção de certos fenômenos, das tempestades, por exemplo, é obra de um só Espírito, ou muitos se reúnem, formando grandes massas, para produzi-los?

9 TADDEI, Renzo, op. cit., p. 202. 
"Reúnem-se em massas inumeráveis."

540. Os Espíritos que exercem ação nos fenômenos da Natureza operam com conhecimento de causa, usando do livre-arbítrio, ou por efeito de instintivo ou irrefletido impulso?

"Uns sim, outros não. Estabeleçamos uma comparação. Considera essas miríades de animais que, pouco a pouco, fazem emergir do mar ilhas e arquipélagos. Julgas que não há aí um fim providencial e que essa transformação da superfície do globo não seja necessária à harmonia geral? Entretanto, são animais de ínfima ordem que executam essas obras, provendo às suas necessidades e sem suspeitarem de que são instrumentos de Deus. Pois bem, do mesmo modo, os Espíritos mais atrasados oferecem utilidade ao conjunto. Enquanto se ensaiam para a vida, antes que tenham plena consciência de seus atos e estejam no gozo pleno do livre-arbítrio, atuam em certos fenômenos, de que inconscientemente se constituem os agentes. Primeiramente, executam. Mais tarde, quando suas inteligências já houverem alcançado um certo desenvolvimento, ordenarão e dirigirão as coisas do mundo material. Depois, poderão dirigir as do mundo moral. É assim que tudo serve, que tudo se encadeia na Natureza, desde o átomo primitivo até o arcanjo, que também começou por ser átomo. Admirável lei de harmonia, que o vosso acanhado espírito ainda não pode apreender em seu conjunto!”’o.

Há muita coisa interessante nesses poucos parágrafos ${ }^{\text {II }}$, mas não é meu objetivo discutir aqui seu conteúdo, e sim os efeitos pragmáticos da interposição de tal texto no fluxo da pesquisa.

O que ocorreu naquele momento foi um curto-circuito existencial-profissional, uma crise que gerou uma situação de paralisia metodológica. Naquele momento, eu, investido na condição e fazendo a performance de homem, branco, acadêmico, antropólogo - desinteressantemente cosmopolita, linguisticamente não marcado, portanto -, realizando pesquisa sobre uma prática "afro-brasileira” e, acima de tudo, interessantíssima em sua inabalável insistência em afrontar a ordem instituída, no que diz respeito aos papéis tradicionalmente atribuídos à ciência e ao conhecimento dito "religioso", quando o assunto é governo e políticas públicas, me dei conta de que não seria possível seguir me esquivando do fato de que meu universo familiar é todo animista - consanguíneos de primeiro grau distribuem-se entre kardecistas (grupo do qual faço parte) e xintoístas.

Como em minha pesquisa anterior, abordei a Fundação Cacique Cobra Coral interessado nas situações de fronteira, onde a equivocação é certa - a sua relação com a política e com a imprensa e, posteriormente, com a ciência. Eu logicamente

IO KARDEC, Allan. O livro dos espíritos. Brasília: Federação Espírita Brasileira, 20I3, p. 262-264.

II Apenas para citar um ponto mais interessante: a racionalidade e o livre-arbítrio são apresentados como parte de um contínuo de transformação dos espíritos, fora da chave dualista que separa mente racional e matéria bruta. Sendo assim, há intencionalidade em tudo, mas é preciso requalificar o que se entende por intencionalidade, neste caso; na prática, isso significa que grande parte da participação espiritual nos fenômenos naturais se dá de forma "mecânica” e, portanto, sujeita aos padrões observáveis no mundo "natural". 
imaginei que, como parte da etnografia, em algum momento iria presenciar a atividade mediúnica, mas nunca me ocorreu fazer dela uma dimensão importante da pesquisa; em outras palavras, ter que responder ao mundo acadêmico se o cacique existe e faz mesmo o que a fundação diz que faz. Aquelas fotocópias das páginas de O livro dos espíritos, no entanto, desestabilizaram todo o esquema metodológico - e, portanto, epistemológico e ontológico - que eu, inconscientemente, havia montado para a pesquisa; e, consequentemente, desorganizaram-se minha performance e a identidade profissional que ela produzia.

$\mathrm{O}$ que houve naquele momento foi sentido por mim, em meio à confusão de conceitos e identidades, como uma reversão de papéis: eu tinha virado índio. Não me refiro aqui ao conceito de índio em qualquer sentido étnico, obviamente; mas em sentido estrutural, na fórmula tradicional da disciplina, antropólogo :: nativo. Eu descobri que, ontologicamente falando, o mundo do nativo e o meu sempre haviam sido o mesmo, enquanto o da "antropologia", esse sim, é que era o diferente. $\mathrm{Eu}$ abordei o mundo do Cacique Cobra Coral esperançoso de que a etnografia permitisse algum entendimento entre nós, ao mesmo tempo que a alteridade permitiria a manutenção das tensões necessárias para a criação conceitual teórica. A alteridade é ao mesmo tempo estratégica e confortável; no momento em que me vi irmanado com o cacique, a etnografia evaporou, e algo completamente inesperado ocorreu: comecei a perceber o arcabouço teórico da antropologia como ameaça. Metáfora, distinção, embodyment, biopoder, weapons of the weak, neurose coletiva, dissociação, histeria, e o que quer mais que seja, podem aniquilar o cacique $^{\mathrm{I2}}$; na verdade, não aniquilam o espírito, aniquilam a conversa - a voz no nativo é calada, e a antropologia fez-se ontologicamente opressora.

Não estou minimizando as muitas divergências existentes entre umbanda e kardecismo (e demais tradições espiritualistas); no entanto, existe uma base ontológica comum que permite facilmente o que Almeida ${ }^{\text {I3 }}$ chamou de acordos pragmáticos, inclusive no que diz respeito a reações à economia das categorias classificatórias, como as científicas. Descola ${ }^{\mathrm{I} 4}$, por exemplo, ao propor seu famoso esquema quadripartite de regimes ontológicos, constrói uma equivalência do tipo

I2 Não há incompatibilidade intrínseca entre essas teorias sociais e a espiritualidade; ocorre, no entanto, que frequentemente essas teorias são usadas exatamente para anular a possibilidade do reconhecimento da espiritualidade, como quando a mediunidade é, sem maiores preocupações em compreender o fenômeno ou escutar os nativos, reduzida a manifestação psíquica oriunda de situações de estresse ou opressão, à guisa de “válvula de escape”. Ver, por exemplo, o clássico OBEYESEKERE, Gananath. Medusa's hair - an essay on personal symbols and religious experience. Chicago: University of Chicago Press, I98I.

I3 ALMEIDA, Mauro William Barbosa. Caipora e outros conflitos ontológicos. R@U: Revista de Antropologia Social dos Alunos do PPGAS-UFSCAR, São Carlos, v. 5, n. I, 20I4, p. 7-28.

I4 DESCOLA, Philippe, op. cit. 
“republicana” ${ }^{\text {I5 }}$ entre as ontologias; Sahlins ${ }^{\mathrm{I} 6}$ sugere, ao gosto estruturalista, que o esquema de Descola pode ser reduzido à díade naturalismo-animismo. Umbanda e kardecismo afirmam que estão ambos equivocados: a ontologia naturalista é um subconjunto da ontologia animista; a segunda é maior que a primeira e a contém. É isso que faz com que a colaboração entre cientistas e o espírito do Cacique não seja (ontologicamente) problemática.

\section{Parte 4}

Enquanto eu tentava formular alguma estratégia para dar conta da situação em que a pesquisa havia caído, chegou a mim um texto de Gersem Baniwa ${ }^{\text {I7 }}$, publicado em livro editado pela Associação Brasileira de Antropologia. Nesse texto, Baniwa faz críticas contundentes à antropologia. Cito a seguir trecho do referido texto:

"[O]s desafios de indígenas antropólogos passam pelos dois sentidos: potencializar as valiosas contribuições da antropologia e dos antropólogos e superar suas imitações ou debilidades, notadamente no campo da tutela e de certo racismo epistêmico. Sobre este último, passo agora a tecer algumas considerações preliminares. Em meu entendimento, o problema da tutela está intrinsecamente relacionado ao etnocentrismo epistemológico dos agentes não indígenas. A visão absolutista da ciência antropológica conduz à prática de tutela cognitiva dos indígenas. Dito de outro modo: os antropólogos não indígenas são excelentes assessores, tutores e aliados políticos, mas mesmo diante de discursos de rupturas não conseguem romper as bases culturais da tutela, do colonialismo e do imperialismo da ciência moderna, na medida em que não são capazes de abrir mão de suas matrizes cosmopolíticas e epistemológicas eurocêntricas ${ }^{18}$.

A experiência com a Fundação Cacique Cobra Coral me permitiu certa identificação com os elementos centrais do argumento de Baniwa. Posteriormente descobri a existência de um grupo grande de autores indígenas, em distintas partes do mundo, cujos argumentos, alinhados aos de Baniwa, são parte de um movimento

I5 Adjetivo usado por Viveiros de Castro ao referir-se à abordagem de Descola. Ver: LATOUR, Bruno. Perspectivism: “Type" or "bomb”?. Anthropology Today, April 2009, v. 25, n. 2, p. I-2. Disponível em: <http:// www.bruno-latour.fr/sites/default/files/P-I/I-DESCOLA-VIVEIROSpdf.pdf>. Acesso em: 23 fev. 2018.

I6 SAHLINS, Marshall. On the ontological scheme of Beyond nature and culture. Hau: Journal of Ethnographic Theory, v. 4, n. I, 20I4, p. 28I-290.

I7 BANIWA, Gersem. Indígenas antropólogos: entre a ciência e as cosmopolíticas ameríndias. In: RIAL, Carmen; SCHWADE, Elisete (Org.). Diálogos antropológicos contemporâneos. Rio de Janeiro: Associação Brasileira de Antropologia, 20I6, p. 47-57.

I8 Ibidem, p. 52. 
maior de descolonização da antropologia. Um dos pioneiros é Vine Deloria Jr. ${ }^{\text {I9, }}$, intelectual sioux que em sua obra é ainda mais duro com a disciplina. Na reunião anual da Associação Americana de Antropologia de 20I5, um grupo de antropólogos indígenas de distintos continentes organizou uma mesa intitulada "Emergent Praxis Against Anthropological Deliriums" ${ }^{20}$; outras mesas e grupos de trabalho na mesma linha têm sido parte dos eventos da disciplina em anos recentes.

O que eu notei, no entanto, é que há, mesmo entre os grupos mais progressistas de etnólogos no Brasil, um imenso desconforto, para dizer o mínimo, frente ao discurso de Baniwa e colegas. E o desconforto é decorrente de uma leitura meramente política, no sentido estrito, o que faz com que se perca a dimensão ontológica da questão. É desconcertante o fato de essa crítica vir de antropólogos indígenas, e não de lideranças indígenas mais tradicionais - estas, aliadas aos antropólogos no campo político, atuam fora do campo acadêmico e aí se constrói a possibilidade de cooperação; aqueles, colegas de academia, desconstroem a disciplina a partir de suas próprias entranhas, e são vistos por alguns como uma ameaça.

\section{Parte 5}

Antes de seguir adiante, talvez seja melhor uma pausa: o leitor pode estar achando a linha argumentativa deste texto algo surreal. Afinal, parece ser consenso que, na história de humanidade, nenhum sistema de ideias foi capaz de descrever e prever os fenômenos da natureza com o grau de precisão com que a ciência o faz; e a ciência nunca foi capaz de documentar, de forma inequívoca, a existência de espíritos. Não seria, então, a tentativa de tomar a sério a existência e ação dos espíritos sobre a atmosfera um ato obscurantista?

Essa pergunta é, obviamente, retórica; mas vale a pena elaborar uma resposta a ela, fazendo uso do próprio pensamento das ciências sociais e humanas da tradição euro-americana.

A ideia de que o argumento deste texto é um contrassenso se baseia em algumas pressuposições. A primeira delas é a percepção de que, como os organismos humanos são todos iguais ${ }^{21}$, é impossível que indígenas vejam e sintam coisas que outros não são capazes de ver e sentir. Indivíduos são obviamente diferentes; mas populações não podem sê-lo, em grandes escalas demográficas (onde se manifestam diferenças chamadas "culturais"); aí o que conta é o fato de serem todos homo sapiens sapiens.

Essa pressuposição é, obviamente, pueril; mas ainda assim se faz presente de forma subterrânea em grande parte dos argumentos que transformam os fenômenos ditos espirituais em metaforização de alguma outra coisa. No livro Myth and

I9 DELORIA JR., Vine. Custer died for your sins: an Indian manifesto. Norman, OK: University of Oklahoma Press, I969.

20 Disponível em: 〈https://www.youtube.com/watch?v=TQt7DNVCKRA〉. Acesso em: 27 dez. $20 I 7$.

2I Concepção essa que é fruto do sucesso tanto da ação antirracista da antropologia na primeira metade do século XX, como da popularização de concepções biologizantes da existência do corpo, na segunda metade. 
meaning ${ }^{22}$, Lévi-Strauss apresenta o caso de índios que eram capazes de ver o planeta Vênus durante o dia, o que para ele era impossível (e inacreditável); posteriormente, o antropólogo encontrou registros de antigos marinheiros europeus que tinham a mesma capacidade. Há dois pontos interessantes aqui: por um lado, a maleabilidade do corpo humano transcende o que supõe o senso comum acadêmico; por outro, crer que os indivíduos das civilizações urbanas ocidentais sejam o pináculo do desenvolvimento corporal e sensorial humano, em termos de suas capacidades, é uma imensa tolice.

Há outra dimensão, mais relevante, todavia, evidenciada tanto pelos estudos sociais da ciência e da tecnologia como pela filosofia da ciência. De certa forma, a ideia de que a ciência possui autoridade para arbitrar o que existe e o que não existe no mundo depende de uma compreensão do método científico como um "descortinamento" do real. Ocorre, no entanto, que essa ideia nunca sobreviveu ao escrutínio de muitos dos principais filósofos da ciência ocidentais, a começar por David Hume, que sugeriu no século XVIII que o método indutivo - pilar fundamental do método científico até os dias atuais - não era capaz de revelar à mente humana nada novo sobre o mundo, uma vez que parte do pressuposto de que o mundo é feito de regularidades e necessita de categorias mentais preexistentes para dar sentido ao que apreende ${ }^{23}$.

Dois séculos mais tarde, Ludwig Wittgenstein ${ }^{24}$ e Paul Feyerabend ${ }^{25}$ argumentaram, de formas distintas, contra a ideia de que a trajetória histórica da ciência - com o arcabouço de conceitos e teorias produzido - é apenas a materialização de um destino necessário, condicionado pela estrutura da natureza; ao contrário, a cada decisão tomada por cientistas ao longo da história (nem todas de caráter lógico ou racional, como demonstrou Wittgenstein ao falar do conceito de elegância ${ }^{26}$ na matemática, por exemplo), inúmeras alternativas foram abandonadas. A história da ciência ocidental é, dessa forma, uma dentre outras possíveis, o que equivale a dizer que é formada por contingências mais do que por necessidade estrutural.

Mais recentemente, os autores ligados à Teoria Ator-Rede demonstraram que a atividade científica não precisa chegar a qualquer "verdade objetiva" para produzir efeitos eficazes no mundo ${ }^{27}$ - a própria noção de verdade objetiva sendo entendida como uma situação em que os níveis de incerteza deixam de causar desconforto cognitivo e funcionam pragmaticamente no que diz respeito às tarefas a serem desenvolvidas, e as controvérsias se estabilizam em níveis administráveis.

Decorre disso tudo a noção de que certas configurações sociotécnicas criam regimes de percepção; e tais regimes de percepção retroalimentam, através de ação

22 LÉVI-STRAUSS, Claude. Myth and meaning. New York: Schocken Books, I979, p. I8.

23 HUME, David. Treatise of human nature. Oxford: Clarendon Press, I888, p. 89.

24 WITTGENSTEIN, Ludwig. Tractatus logico-philosophicus. New York: Routledge, 2001.

25 FEYERABEND, Paul. Against method. London: Verso, I993.

26 WITTGENSTEIN, Ludwig. Philosophical grammar. Berkeley: University of California Press, 2005, p. 462.

27 LATOUR, Bruno, I994, op. cit; STENGERS, Isabelle. Cosmopolitics Vol. I. Minneapolis: University of Minnesota Press, 2010. 
concertada dos membros da coletividade - inclusive na forma como agenciamentos maquínicos são evocados e postos para funcionar -, os elementos que garantem o funcionamento das mesmas redes sociotécnicas. A autópsia de um mamífero, por exemplo, jamais encontrou uma alma - não porque o mamífero não a tenha, mas porque a técnica da autópsia é parte de uma forma de organização e agenciamento da realidade que parte do pressuposto de que a alma não existe. Nenhuma autópsia pode, dessa forma, provar a existência ou a inexistência da alma. Nesse pequeno exemplo reside o elemento fundamental da questão: o fato de o mundo ocidental moderno funcionar bem com seu arcabouço de ideias e instituições não diz nada a respeito dos mundos em que outros povos vivem e dos fenômenos que produzem no viver em tais mundos. Quando a ciência se põe a legislar sobre o que pode e o que não pode existir nos mundos não ocidentais, está usando autópsias para provar a inexistência da alma; Stengers chamou isso de "máquina de guerra das ciências"28.

Essa atitude das ciências ocidentais não é mera má vontade. O materialismo que as caracteriza desenvolveu-se em um contexto histórico em que ao capitalismo, nascido praticamente no mesmo lugar e no mesmo momento, interessava o esvaziamento espiritual da natureza ${ }^{29}$, de modo a poder transformá-la em matéria-prima. O mundo moderno é fruto de agenciamentos mútuos entre a ciência nascente e o capitalismo em desenvolvimento; agenciamentos esses que foram constituindo, lentamente, novos regimes de percepção e novas ideias deles decorrentes. A Europa foi capaz de transformar sua configuração religiosa de modo a investir na divindade deslocada que não atrapalha a produção e o comércio, e ao mesmo tempo exterminou as tradições animistas, com suas entidades espirituais ligadas aos rios, às florestas, aos animais e às montanhas. Se atualmente, nas três Américas, movimentos de revitalização de tradições animistas são capazes de fazê-lo com algum grau de continuidade histórica, o mesmo não se dá, por exemplo, nos movimentos Wicca e Druidry na Inglaterra.

O argumento central aqui é que os principais regimes de percepção encontrados dentro dos laboratórios científicos e dos auditórios universitários são herdeiros dessa combinação histórica, aqui apenas rascunhada, entre a forma como os trabalhos dos primeiros cientistas foram acomodados nas sociedades europeias, com a associação da crescente matematização do mundo às metáforas raiz ${ }^{30} \mathrm{de}$ cada época (sendo a "máquina" uma das mais importantes no século XVII); o interesse da produção capitalista pela transformação dos sentimentos ligados às florestas, rios e montanhas, de modo a poder transformá-los em recursos econômicos; e a forma como a espiritualidade assume um viés de transcendência platônica, de modo a estrategicamente manter a divindade, a uma só vez, moralmente presente e materialmente ausente.

Isso define o que os corpos dos cientistas, em associação com suas máquinas, estratégias cognitivas, teorias e instituições, são capazes de perceber e fazer; e também o que são incapazes de perceber e fazer.

28 STENGERS, Isabelle. Cosmopolitics Vol. I, op. cit.

29 STARHAWK, neste volume.

30 ORTNER, Sherry B. On key symbols. American Anthropologist 75, I973, p. I338-I346. 


\section{DISCUSSÃO}

Há, dentro do discurso antropológico, e das ciências humanas de forma geral, o antídoto para os problemas aqui apresentados: conexões parciais, conhecimento localizado, ciborgue, paroquialização das ciências etc. Os antropólogos indígenas, obviamente, têm conhecimento disso tudo. Por que, então, as acusações de colonialismo seguem sendo enunciadas? Repito, aqui, um trecho da fala de Gersem Baniwa: "mesmo diante de discursos de rupturas [os antropólogos] não conseguem romper as bases culturais da tutela, do colonialismo e do imperialismo da ciência moderna”3I. Ou seja, há na disciplina um discurso de ruptura, mas que não se mostra eficaz no que diz respeito à transformação das práticas da disciplina.

Vejamos, por exemplo, a questão dos congressos, talvez o mais importante ritual no processo de reprodução da institucionalização da disciplina no Brasil e em outros países. De forma esquemática, a despeito de tentativas tímidas de debate e transformação no modelo com que são estruturadas tais reuniões, este continua se baseando na sequência interminável de apresentações verbais, em tempos de I5 minutos cada, em que se objetiva apresentar resultados de investigação. Como é possível discutir, de forma tão compacta e em dinâmica inspirada em linhas de montagem industrial, toda a complexidade das experiências etnográficas vividas? Como fazer justiça à densidade das relações com os demais partícipes na vivência etnográfica? Aqui, o processo de culturalização, ou de antropologização, de algo funciona como estratégia de redução, compactação e tradução da experiência em performance para congressos ou em conteúdo para artigos. Obviamente reside aí o perigo de aniquilação ontológica, e, portanto, política, de parte dos mundos em que ocorreu a vivência etnográfica.

De forma geral, não se leva em consideração que as coletividades onde acontecem as vivências etnográficas estão organizadas em torno de práticas e formas de vida cuja experiência efetiva exige muito mais do que o aprendizado da língua, a permanência por todo o ciclo do calendário local e a boa vontade das lideranças. Muitas vezes, tais práticas exigem, além de décadas de aprendizado, o abandono de estratégias e práticas habituais de autoconstituição (inclusive corporal e mental32), coisa que antropólogos em geral não estão dispostos a fazer. Por essa razão os trabalhos etnográficos refletem, frequentemente, o pesquisador muito mais do que o pesquisado - especialmente quando o tema é transe, xamanismo e mediunidade.

Podemos ir ainda mais adiante. As coletividades podem dizer coisas e colocar questões sobre suas próprias realidades a respeito das quais a ciência - antropologia aí incluída - não tem nada a dizer. É prática comum na antropologia a pressuposição de que os mundos socioculturais são acessíveis por princípio; podem ser complexos como o parentesco amazônico ou como as trocas econômicas na Melanésia, mas se assume, como corolário, que tais coisas e tudo o mais, no âmbito sociocultural, são, por definição, acessíveis à investigação etnográfica. Na prática, isso pressupõe

3I BANIWA, Gersem, op. cit., p. 52.

32 TADDEI, Renzo; GAMBOGGI, Ana Laura. Education, anthropology, ontologies. Educação e Pesquisa - Revista

da Faculdade de Educação da USP, v. 42, n. I, 20I6, p. 27-38. 
a ontologia naturalista que caracteriza as tais ciências ocidentais ditas "duras". Quando a antropologia evita a questão ontológica, ela reproduz o naturalismo que compartilha com as ciências duras (e com o capitalismo).

Há ainda uma versão mais radical dessa questão, que se manifesta quando o(a) antropólogo(a) faz afirmações categóricas sem que seja capaz de justificar o que diz sequer dentro do universo epistemológico em que supostamente atua. Isso se dá, por exemplo, quando a narrativa etnográfica dá a entender ou afirma explicitamente que conhece a "natureza" dos espíritos, e que esta reside na incorporação - ou seja, que se trata apenas de performance e que não existem espíritos se não estiverem incorporados ${ }^{33}$. Outra variedade do mesmo fenômeno é aquele que equaliza a possessão espiritual a doenças mentais - mais uma declaração bastante explícita de que os espíritos, na realidade, não existem ${ }^{34}$.

A antropologia constituiu para si um jogo de linguagem muito particular, em que se exime de justificar-se tanto para os colegas de academia como para os interlocutores de etnografia. Através de um exercício de antropologia reversível (não apenas reversa, mas um em que o etnógrafo efetivamente habita os dois mundos), é possível mostrar que o conceito de "natureza" usado em expressões como "por sua própria natureza, os espíritos..." não tem equivalência com qualquer outra forma de construir discurso de autoridade sobre a natureza no mundo acadêmico (através do uso de critérios de cientificidade, por exemplo), e muito menos com o dos interlocutores etnográficos - ou seja, trata-se da antropologia naturalista em sua própria ontogênese particular. No caso da ideia de doença mental, os autores, salvo raríssimas exceções, se eximem da constituição de aliança consistente com a (ou contra a) psiquiatria e usam a ideia de doença de forma leviana, sem que os efeitos pragmáticos disso sejam considerados. Por fim, a afirmação categórica de que os espíritos não existem, frente à impossibilidade de que isso seja sequer verificável empiricamente dentro do regime ontológico dominante no mundo acadêmico e na antropologia, revela que se trata de uma profissão de fé, mais do que qualquer outra coisa.

Sigamos adiante. Há, também, a questão do lugar da enunciação. Em congresso recente ${ }^{35}$, durante o debate que se seguiu a uma mesa sobre antropologia e mudanças climáticas, após várias participações do público no auditório presente, um antropólogo indígena tomou o microfone e iniciou sua fala dizendo: "eu falo na condição de antropólogo tukano”. Imediatamente me chamou a atenção que ninguém, antes dele, havia feito uma autoapresentação que explicitasse o seu lugar de fala. Pois esse é um elemento constitutivo dos congressos e artigos: o "cosmopolitismo de fundo”, que funciona como mecanismo tácito de comensurabilização de tudo o que ali existe e é apresentado. Tal cosmopolitismo de fundo exime a todos da necessidade da explicitação do lugar de fala, e o faz em razão do fato de estar fundado

33 CARDOSO, Vânia Zikàn. Spirits and stories in the crossroads. In: BLANES, Ruy; ESPÍRITO SANTO, Diana (Org.). The social life of spirits. Chicago: The University of Chicago Press, 20I4.

34 GOLDMAN, Márcio. Cosmopolíticas, etno-ontologías y otras epistemologías. La antropología como teoría etnográfica. Cuadernos de Antropología Social, 44, 2016, p. 27-35.

35 VI Reunião de Antropologia da Ciência e da Tecnologia, realizada no Instituto de Estudos Brasileiros da Universidade de São Paulo, entre os dias I6 e I9 de maio de 2017. 
no mononaturalismo das ciências ocidentais. Em função disso, essa antropologia cosmopolita, apesar de sua pretensão política progressista, não consegue ir além da mera reprodução da agenda humanista liberal e do que Stengers chamou de "maldição da tolerância"36.

Dessa forma, chega-se à conclusão de que a antropologia é parte da "máquina de guerra da ciência" de que nos fala Stengers, onde "conhecimento" e "cultura" são usados como armas neutralizadoras. Os 350 anos de materialismo desencantado produziu certa dessensibilização coletiva para muitas dimensões da vida, fazendo com que grandes contingentes acadêmicos integrem, sem se dar conta, as burocracias perpetradoras das muitas "banalidades do mal”, seja em sua variação ambiental ${ }^{37}$, seja na variedade "culturalizadora".

A antropologia produzida por intelectuais indígenas tem o mérito de desnaturalizar o fato de se "ser antropólogo" - ou seja, se é o adjetivo "indígena" o marcador que chama a atenção inicialmente, a etapa seguinte, mais interessante, é o desmonte da caixa-preta "antropólogo". Mas o que há aí, na atuação desses antropólogos indígenas? Pelo menos dois elementos: em primeiro lugar, a valorização das atividades práticas em oposição a elaborações teóricas. Não é à toa que é recorrente no discurso dos antropólogos indígenas a valorização da atividade pedagógica, e o relativo desinteresse pela atividade de "produção de ciência" ${ }^{8}$. Em segundo lugar está a importância atribuída às dimensões de trajetória e presença no mundo, em oposição a abstrações conceituais descontextualizadas. A indexicalidade radical do fazer antropológico indígena é, como mostram Gersem Baniwa e inúmeros outros, incompatível com o emprego retórico de um "nós" genérico, que subentende uma identidade e uma ontologia, como se vê em inúmeros textos reflexivos que versam sobre a disciplina.

No que diz respeito às implicações que isso tudo tem na antropologia, pode-se vislumbrar alguns elementos imprescindíveis ao debate. Um deles foi mencionado por Latour ${ }^{39}$ quando disse que o desafio trazido pelo perspectivismo ameríndio não é uma "virada", mas sim uma explosão - efetivamente, o que se busca na crítica à antropologia colonialista não é a aniquilação da antropologia feita sobre bases ontológicas naturalistas, mas a redução dela a uma antropologia dentre inúmeras outras. Antropólogas e antropólogos não escolhem suas matrizes cosmopolíticas por decisão racional; inverter os sinais da relação colonial apenas reproduz o colonialismo. Essa, naturalmente, não é a intenção da maioria dos ativistas trabalhando pela descolonização da antropologia.

Márcio Goldman, em texto recente, sugere que, a partir de uma perspectiva

36 STENGERS, Isabelle. Cosmopolitics Vol. 2. Minneapolis: University of Minnesota Press, 20II.

37 HARAWAY, Donna. Anthropocene, Capitalocene, Chthulucene: staying with the trouble. Apresentação na conferência Arts of Living on a Damaged Planet, Aarhus, Dinamarca, 9/5/2014. Disponível em: <https://vimeo. com/97663518>. Acesso em: I8 ago. 20I4.

38 Ver, por exemplo: BENITES, Tonico. Trajetória e atuação de um antropólogo indígena. In: RIAL, Carmen; SCHWADE, Elisete (Org.). Diálogos antropológicos contemporâneos. Rio de Janeiro: Associação Brasileira de Antropologia, 2016, p. 59-67.

39 LATOUR, Bruno, 2009, op. cit. 
naturalista, a transformação da antropologia virá da adoção de uma postura que adota como guia um "não saber" transcendental ${ }^{40}$. Essa postura, me parece, é bastante mais apropriada do que a sugerida por Henare, Holbraad \& Wastell ${ }^{4 \mathrm{I}} \mathrm{e}$ também por Holbraad \& Pedersen ${ }^{42}$, onde o que se propõe é o uso de uma abordagem ontológica de modo a expandir o arcabouço conceitual da antropologia - o que, de certa forma, sugere a ambição de fazê-la hipercosmopolita. O que a descolonização da antropologia anseia, ao invés disso, é o abandono definitivo do mencionado cosmopolitismo de fundo que marca as relações profissionais institucionalizadas; de disciplina, a antropologia se transformará em plataforma de relações cosmopolíticas.

Dessa forma, o primeiro passo na descolonização da disciplina é explodi-la; o segundo, o incentivo à formação, por parte dos fragmentos daí resultantes, de aglomerados territorializados, relacionados entre si de forma mais rizomática e menos arbórea, de modo que mesmo os termos naturalismo e animismo, usados de forma tão extensiva neste texto, deixem de fazer sentido; o terceiro passo consiste em trabalhar na construção de acordos pragmáticos (equivocações desejáveis), que são sempre locais, efêmeros (por isso requerem atenção e trabalho) e objetivamente focados. A antropologia precisa ser paroquial, ter marcas visíveis de nascença e desenvolvimento, ser uma atividade diplomática difícil.

No momento em que tal transformação se efetuar, uma ocasião em que alguém apresentar algo em um congresso ou escrever um artigo sem declarar-se, em termos de lugar de fala dentro desse rizoma, será considerada como ato de violência ontológica.

\section{SOBRE O AUTOR}

RENZO TADDEI é professor de Antropologia no Instituto do Mar e no Programa de Pós-Graduação em Ciências Sociais da Universidade Federal de São Paulo (Unifesp) e pesquisador associado na Universidade Colúmbia, em Nova York. E-mail: renzo.taddei@unifesp.br

40 GOLDMAN, Márcio, op. cit., p. 34.

4I HENARE, Amiria; HOLBRAAD, Martin; WASTELL, Sari. Thinking through things: theorising artefacts in ethnographic perspective. London: Routledge, 2007.

42 HOLBRAAD, Martin; PEDERSEN, Morten Axel. The ontological turn: an anthropological exposition. Cambridge: Cambridge University Press, 2017. 


\section{REFERÊNCIAS BIBLIOGRÁFICAS}

ALMEIDA, Mauro William Barbosa. Caipora e outros conflitos ontológicos. R@U: Revista de Antropologia Social dos Alunos do PPGAS-UFSCAR, São Carlos, SP, v. 5, n. I, 20I4, p. 7-28.

BANIWA, Gersem. Indígenas antropólogos: entre a ciência e as cosmopolíticas ameríndias. In: RIAL, Carmen; SCHWADE, Elisete (Org.). Diálogos antropológicos contemporâneos. Rio de Janeiro: Associação Brasileira de Antropologia, 2016.

BENITES, Tonico. Trajetória e atuação de um antropólogo indígena. In: RIAL, Carmen; SCHWADE, Elisete (Org.). Diálogos antropológicos contemporâneos. Rio de Janeiro: Associação Brasileira de Antropologia, 20I6, p. 59-67.

BOULTING, Gideon et al. Série O infiltrado, episódio n.9-Magia. History Channel. Disponível em: <https:// www.youtube.com/watch?v=ESh54fsi8iU >. Acesso em: 27 dez. 2017.

CARDOSO, Vânia Zikàn. Spirits and stories in the crossroads. In: BLANES, Ruy; ESPÍRITO SANTO, Diana (Org.). The social life of spirits. Chicago: The University of Chicago Press, 20I4.

DELORIA JR., Vine. Custer died for your sins: an Indian manifesto. Norman, OK: University of Oklahoma Press, I969.

DESCOLA, Philippe. Beyond nature and culture. Chicago: The University of Chicago Press, 2013.

FEYERABEND, Paul. Against method. London: Verso, I993.

GOLDMAN, Márcio. Cosmopolíticas, etno-ontologías y otras epistemologías. La antropología como teoría etnográfica. Cuadernos de Antropología Social, 44, 2016, p. 27-35.

HARAWAY, Donna. Anthropocene, Capitalocene, Chthulucene: staying with the trouble. Apresentação na conferência Arts of Living on a Damaged Planet, Aarhus, Dinamarca, 9/5/2014. Disponível em: <https://vimeo.com/976635I8>. Acesso em: I8 ago. 20I4.

HENARE, Amiria; HOLBRAAD, Martin; WASTELL, Sari. Thinking through things: theorising artefacts in ethnographic perspective. London: Routledge, 2007.

HOLBRAAD, Martin; PEDERSEN, Morten Axel. The ontological turn: an anthropological exposition. Cambridge: Cambridge University Press, 2017.

HUME, David. Treatise of human nature. Oxford: Clarendon Press, I888.

KARDEC, Allan. O livro dos espíritos. Brasília: Federação Espírita Brasileira, 2013.

KOPENAWA, Davi; ALBERT, Bruce. A queda do céu: palavras de um xamã yanomami. São Paulo: Companhia das Letras, 2015.

LATOUR, Bruno. Jamais fomos modernos: ensaio de antropologia simétrica. Rio de Janeiro: Ed. 34, I994

. Perspectivism: “Type” or "bomb”?. Anthropology Today, April 2009, v. 25, n. 2, p. I-2. Disponível em: 〈http://www.bruno-latour.fr/sites/default/files/P-I4I-DESCOLA-VIVEIROSpdf.pdf >. Acesso em: 23 fev. 2018.

LÉVI-STRAUSS, Claude. Myth and meaning. New York: Schocken Books, I979.

MUNDURUKU, Daniel. Índio não existe. Global Editora, julho 20I7. Disponível em: <http://www.globaleditora.com.br/blog/estante-global/daniel-munduruku-indio-nao-existe2〉. Acesso em: 27 dez. 2017. NEVES, Marcos Eduardo. Vendedor de sonhos: a vida e a obra de Roberto Medina. São Paulo: Editora Melhoramentos, 2006.

OBEYESEKERE, Gananath. Medusa's hair - an essay on personal symbols and religious experience. Chicago: University of Chicago Press, I98I.

ORTNER, Sherry B. On key symbols. American Anthropologist 75, I973, p. I338-I346. 
SAHLINS, Marshall. On the ontological scheme of Beyond nature and culture. Hau: Journal of Ethnographic Theory, v. 4, n. I, 20I4, p. 28I-290.

STENGERS, Isabelle. Cosmopolitics Vol. I. Minneapolis: University of Minnesota Press, 2010. . Cosmopolitics Vol. 2. Minneapolis: University of Minnesota Press, $201 I$.

TADDEI, Renzo. Alter geoengenharia. In: . Meteorologistas e profetas da chuva: conhecimentos, práticas e políticas da atmosfera. São Paulo: Terceiro Nome, 20I7, p. I89-205.

; GAMBOGGI, Ana Laura. Education, anthropology, ontologies. Educação e Pesquisa - Revista da Faculdade de Educação da USP, v. 42, n. I, 20I6, p. 27-38.

TAS, Marcelo. Cacique Cobra Coral: medalha de ouro na abertura da Olimpíada. Blog do Tas, 28/12/20I2. Disponível em: $<$ http://blogdotas.com.br/20I2/o7/28/cacique-cobra-coral-medalha-de-ouro-na-abertura-da-olimpiada $>$. Acesso em: 27 dez. 2017.

TENGAN, Ty P. K.; PERLEY, Bernard. Emergent praxis against anthropological deliriums. Mesa-redonda ocorrida na reunião anual da American Anthropological Association, 2015. Disponível em: <https:// www.youtube.com/watch?v=TQt7DNVCKRA >. Acesso em: 27 dez. 2017.

VIVEIROS DE CASTRO, Eduardo. O recado da mata. In: KOPENAWA, Davi; ALBERT, Bruce. A queda do céu: palavras de um xamã yanomami. São Paulo: Companhia das Letras, 2015.

WITTGENSTEIN, Ludwig. Tractatus logico-philosophicus. New York: Routledge, 200I. . Philosophical grammar. Berkeley: University of California Press, 2005. 